\title{
Sediment transport processes at the head of Halibut Canyon, Eastern Canada margin: An interplay between internal tides and dense shelf water cascading.
}

\author{
Pere Puig (1), Blair J.W. Greenan (2), Michael Z. Li (3), Robert H. Prescott (4), and David J.W. Piper (3) \\ (1) Institut de Ciències del Mar (CSIC). Passeig Marítim de la Barceloneta, 37-49. 08003 Barcelona, Spain, (2) Fisheries and \\ Oceans Canada, Bedford Institute of Oceanography. P.O. Box 1006, Dartmouth, Nova Scotia, B2Y 4A2, Canada, (3) \\ Geological Survey of Canada (Atlantic), Bedford Institute of Oceanography. P.O. Box 1006, Dartmouth, Nova Scotia, B2Y \\ 4A2, Canada, (4) Prescott and Zou Consulting. 6 Glenn Dr. Halifax, Nova Scotia, B3M 2B9, Canada
}

To investigate the processes by which sediment is transported through a submarine canyon incised in a glaciated margin, the bottom boundary layer quadrapod RALPH was deployed at 276-m depth in the West Halibut Canyon (off Newfoundland) during winter 2008-2009. Two main sediment transport processes were identified throughout the deployment. Firstly, periodic increases of near-bottom suspended-sediment concentrations (SSC) were recorded associated with the up-canyon propagation of the semidiurnal internal tidal bore along the canyon axis, carrying fine sediment particles resuspended from deeper canyon regions. The recorded SSC peaks, lasting less than one hour, were observed sporadically and were linked to bottom intensified up-canyon flows concomitant with sharp drops in temperature. Secondly, sediment transport was also observed during events of intensified down-canyon current velocities that occurred during periods of sustained heat loss from surface waters, but were not associated with large storms. High-resolution velocity profiles throughout the water column during these events revealed that the highest current speeds $(\sim 1 \mathrm{~m} \mathrm{~s}-1)$ were centered several meters above the sea floor and corresponded to the region of maximum velocities of a gravity flow. Such flows had associated low SSC and cold water temperatures and have been interpreted as dense shelf water cascading events channelized along the canyon axis. Sediment transport during these events was largely restricted to bedload and saltation, producing winnowing of sands and fine sediments around larger gravel particles. Analysis of historical hydrographic data suggests that the origin of such gravity flows is not related to the formation of coastal dense waters advected towards the canyon head. Rather, the dense shelf waters appear to be generated around the outer shelf, where convection during winter is able to reach the sea floor and generate a pool of near-bottom dense water that cascades into the canyon during one or two tidal cycles. A similar transport mechanism can occur in other submarine canyons along the eastern Canadian margin, as well in other canyoned regions elsewhere, where winter convection generally reaches the shelf-edge. 